NASZA DERMATOLOGIA Online OUR DERMATOLOGY Online

Source of Support: Nil

Competing Interests: None

\section{STRICT ANATOMICAL CO EXISTENCE AND COLOCALIZATION OF VITILIGO AND PSORIASIS - A RARE ENTITY}

\author{
Neerja Puri, Asha Puri \\ Department of Dermatology and Venereology, Punjab Health Systems Corporation, \\ Ferozepur, Punjab, India
}

Corresponding author: Dr. Neerja Puri

neerjaashu@rediffmail.com

\begin{abstract}
The coexistence of psoriasis and vitiligo is rare. We describe a case report of a 58 year old female patient who developed typical psoraiatic plaques covering completely or partly the vitiliginous areas of her skin. Her psoriasis was strictly limited to the vitiliginous patches with no involvement of the normal skin. Strict anatomical coexistence of both diseases is extremely rare and suggests a casual mechanism, possibly due to a koebner phenomenon but genetic and environmental factors may also be involved.
\end{abstract}

Key words: autoimmune; colocalization; koebner phenomenon; patch; psoriasis; vitiligo

\section{Introduction}

The occurrence of psoriasis in patients with vitiligo has not been often described [1-3]. Vitiligo and psoriasis are common conditions with a prevalence of approximately $1 \%$ and $3 \%$ respectively $[4,5]$ and may be present in the same person. Patients with vitiligo and psoriasis may have the koebner phenomenon [3]. In 1982, Koransky and Roenig described the association of vitiligo and psoriasis to be rare $[6,7]$. The increased incidence of presumably autoimmune diseases in patients with vitiligo and psoriasis is an evidence of the autoimmune origin of these two conditions [8].

\section{Case Report}

A 58 year female reported to the department of dermatology with depigmented patch over axilla, neck, breast and groins, arms, forearm, elbows, hands, fingers, legs \& thighs since 6 years. Patient noticed erythematous plaques with thick scaling over extensors and scalp since 2 years. Cutaneous examination revealed well defined and erythematous papules and plaques with silvery scales over arm, forearm, elbows, hands (Fig. 1), fingers, legs and thighs. There was mild pruritis present over lesions. There was cohabitation of psoriatic lesions over vitiligo patches. The PASI score of the patient was 12 . Auspitz sign was positive.

A clinical diagnosis of coexistent vitiligo and psoriasis was made. On cutaneous examination, there were present thick plaque on the wrist over a depigmented patch measuring $8 \mathrm{~cm}$ $\mathrm{x} 6 \mathrm{~cm}$ in diameter. The plaque had thick silvery scaling. The depigmented patches were present over the tips of fingers, over central part of buttocks $(10 \mathrm{~cm} \times 8 \mathrm{~cm})$ measuring $10 \mathrm{~cm}$ $\mathrm{x} 8 \mathrm{~cm}$, over both axilla (right axilla $7 \mathrm{~cm} \times 6 \mathrm{~cm}$ and left axilla $8 \mathrm{~cm} \times 5 \mathrm{~cm}$ ) and groins and breast (right breast $5 \mathrm{~cm} \times 3 \mathrm{~cm}$ and left breast $4 \mathrm{~cm} \times 4 \mathrm{~cm}$ ). The nail showed pitting, beaus lines and longitudinal striations. All the investigations of the patient were within normal limits except the ESR which was $48 \mathrm{~mm}^{1 \mathrm{st}}$ hour. A clinical diagnosis of psoriasis in association with vitiligo was made.

Two skin biopsies of the patient were taken from the localized lesion. The skin biopsy taken from left elbow showed neutrophilic crust and parakeratosis. Epidermis showed loss of granular layer and elongation of rete ridges with suprapapillary thinning of the epidermis (Fig. 2). Dilated capillaries and papillary dermal oedema were seen. Lymphohistiocytic infiltrate was noted.

So, the biopsy from left elbow was consistent with psoriasis. The second biopsy was taken at the site of depigmented patch over the left elbow. The histopathological findings were as follows: Architecturally normal epidermis showed intact basal layer. Mild lymphohistiocytic infiltrate was present in the papillary dermis. There was an absenceof melanocytes in the basal cell layer confirmed by special staining (Fig. 3). There was inflammation at the dermoepidermal junction. The clinical features were consistent with colocalized vitiligo and psoriasis. 
The patient was put on melanocyl $0.6 \mathrm{mg} / \mathrm{kg}$ body weight on alternate days, but patient complained of increased photosensitivity with aggravation of lesions after a few weeks of treatment. Subsequently, the patient was put on methotrexate $0.2 \mathrm{mg} / \mathrm{kg}$ body weight. The response started appearing within two weeks of treatment.

The psoriatic lesions cleared upto 6 weeks after treatment with methotrexate (with a drop of PASI score to 3.2), but the repigmentation in vitiligo lesions took a longer time. After 12 weeks of treatment, the vitiligo patches showed mild repigmentation (Fig. 4). The patient is still on treatment for vitiligo and is on a regular follow up.

\section{Discussion}

In our case, the patient first presented with vitiligo and later psoriasis developed at the site of vitiligo. Papdavid et al. [3] stated that in cases of psoriasis limited to areas of vitiligo, their coexistence resulted from koebner phenomenon. Several studies indicated a polygenic model for vitiligo [9] and psoriasis $[10,11]$.

Many susceptibility loci of psoriasis [12] and vitiligo $[13,14]$ have been mapped and the subsequently locus for vitiligo. AISI, in chromosome IP 31, is situated close to the susceptibility locus for psoriasis PSORS7 [13].

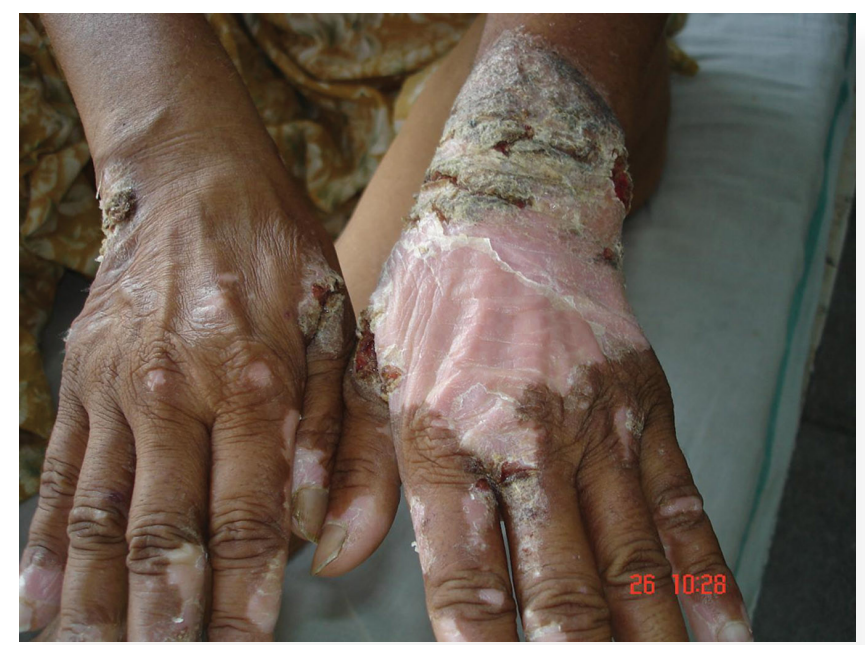

Figure 1. Scaly plaque on the wrist over a depigmented patch before treatment

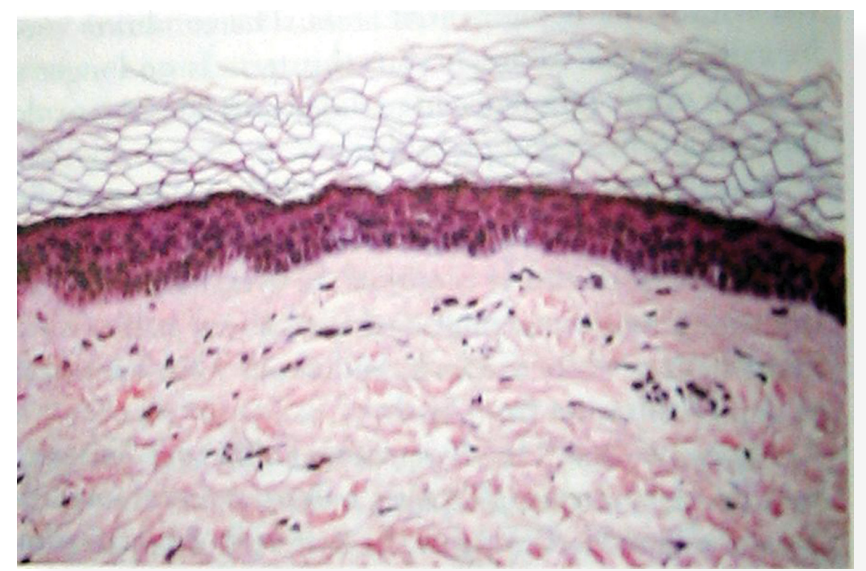

Figure 3. Photomicrograph of depigmented patch showing absence of melanocytes in the basal layer
Nevertheless, the possibility of loci being identical is minimized by the low prevalence of psoriasis in patients with vitiligo.

In 1989, Menter et al reported the first possible case of psoriasis guttate restricted to areas of vitiligo. In 1998, Dhar and Malaks described the first likely case of vitiligo associated with psoriasis in a pediatric patient, a nine year old boy [15].

The hypothesis that generalized vitiligo [16] is an autoimmune process is based principally on its association with other presumably immunologic disorders and demonstration of antimelanocyte antibody. Co-habitation of two disorders which possess a prominent immunological component in their pathogenesis may offer a clue as their causation [17].

To conclude, we report the co-existence of vitiligo and psoriasis with few colocalized lesions. Many pigment cell biologists and dermatologists have concluded that vitiligo is an autoimmune disease and psoriasis, the T cell mediated skin disease [18], may be associated. Whether their interpretation of the association is valid is uncertain. This requires further insight into their pathogenesis, as we believe that psoriasis and vitiligo are spectra of diseases with varied etiology for varied clinical presentation [19].

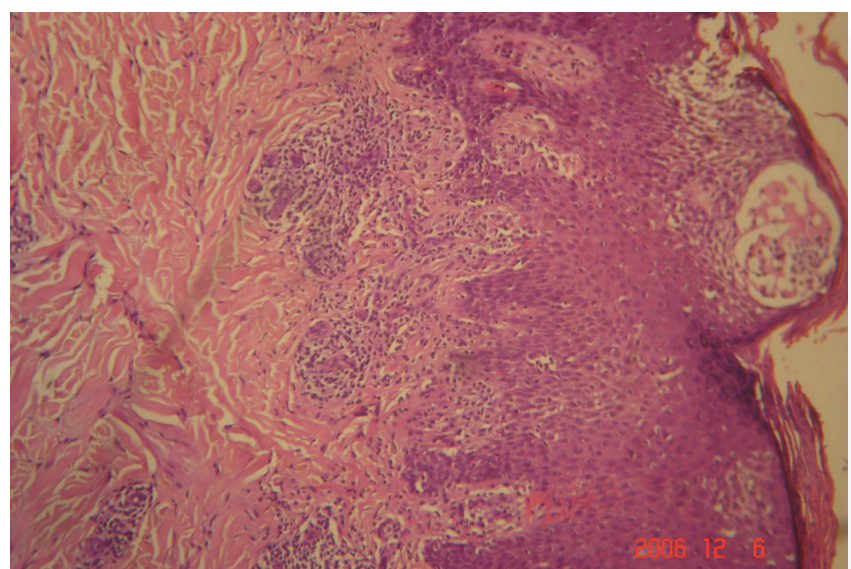

Figure 2. Photomicrograph of psoriatic plaque showing micromunro abscess $\mathrm{H} \& \mathrm{E}$ stain

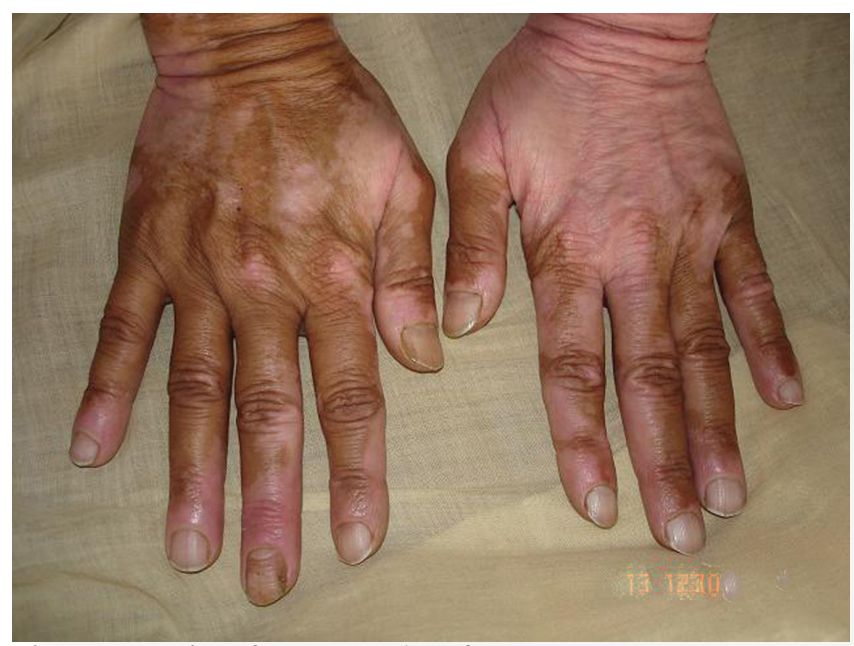

Figure 4. Wrist after 12 weeks of treatment 


\section{REFERENCES}

1. Koransky JS, Roenigk HHJ: Vitiligo and psoriasis. J Am Acad Dermatol. 1982;7:183-9.

2. Menter A, Boyd AS, Silverman AK: Gutate psoriasis and vitiligo: anatomic cohabitation. J Am Acad Dermatol. 1989;20:698-700.

3. Papadavid E, Yu RC, Munn S, Chu AC: Strict anatomical coexistence of vitiligo and psoriasis vulgaris-a Koebner phenomenon? Clin Exp Dermatol. 1996;21:138-40.

4. Lerner AB, Vitiligo J: Invest Dermatol. 1959;32:285-310.

5. Brandrup F, Green A: The prevalence of psoriasis in Denmark. Acta Derm Venereol. 1981;61:344-6.

6. Castanet J, Ortonne JP: Pathophysiology of vitiligo. Clin Dermatol. 1997;1:845-51.

7. Bor S, Feiwel M, Chanarin I: Vitiligo and its aetiological relationship to organ-specific autoimmune disease. Br J Dermatol. 1969;81:83-8.

8. Arcos-Burgos M, Parodi E, Salgar M, Bedoya E, Builes JJ, Jaramillo D, et al: Vitiligo: complex segregation and linkage disequilibrium analyses with respect to microsatellite loci spanning the HLA. Hum Genet. 2002;110:334-42.

9. Nath SK, Majumder PP, Nordlund JJ: Genetic epidemiology of vitiligo: multilocus recessivity cross-validated. Am J Hum Genet. 1994; 55:981-90.

10. Pietrzyk JJ, Turowski G, Kapinska-Mrowka M, Rozanski B: Family studies in psoriasis. I. Complex segregation analysis. Arch Derm Res. 1982; 273:287-94.
11. Swanbeck G, Inerot A, Martinsson T, Wahlstrom J: A population genetic study of psoriasis. Br J Dermatol. 1994;131:32-9.

12. International Psoriasis Genetics Consortium. The International Psoriasis Genetics Study: assessing linkage to 14 candidate susceptibility loci in a cohort of 942 affected sib pairs. Am J Hum Genet. 2003;73:430-7.

13. Fain PR, Gowan K, LaBerge GS, Alkhateeb A, Stetler GL, Talbert J, et al: A genomewide screen for generalized vitiligo confirmation of AIS1 on chromosome $1 \mathrm{p} 31$ and evidence for additional susceptibility loci. Am J Hum Genet. 2003;72:1560-4.

14. Spritz RA, Gowan K, Bennet DC, Fain PR: Novel Vitiligo susceptibility loci on chromosome 7(AIS2) and 8(AIS3), confirmation of SLEV1 on chromosome 17, and their roles in an autoimmune diathesis. Am J Hum Genet. 2004;74:188-91.

15. Dhar S, Malakar S, Dhar S: Colocalisation of vitiligo and psoriasis in a 9-year-old boy. Pediatr Dermatol. 1998;15:242-3.

16. El Mofty AM, El Mofty M: Vitiligo: a symptom complex. Int J Dermatol. 1980;19:237-44.

17. Julian GC, Bowers PW: Strict anatomical coexistence of vitiligo and psoriasis vulgaris - a koebner phenomenon? Clin Exp Dermatol. 1996;6:464-464.

18. Musset P, Bachelez M, Ilageve B, Delarbre C, Kowielsky P, Dubertret L, et al: Immune-mediated destruction of melanocytes in halo nevi is associated with the local expansion of a limited number of T cells clones. The J Immunol. 1999;162:1789-94.

19. TG Berger, F Kiesewetter, C Maczek, N Bauer, M Lueftl, G Schuler: Psoriasis confined strictly to vitiligo areas - a Koebner-like phenomenon? J Eur Acad Dermatol Venereol. 2006;20:178-83.

Copyright by Neerja Puri, et al. This is an open access article distributed under the terms of the Creative Commons Attribution License, which permits unrestricted use, distribution, and reproduction in any medium, provided the original author and source are credited. 